\title{
Combined therapy with ceftriaxone and doxycycline does not improve the outcome of meningococcal meningitis in mice compared to ceftriaxone monotherapy
}

Susanna Ricci ${ }^{1,2^{*}}$ D, Denis Grandgirard ${ }^{3,2}$, Ilias Masouris ${ }^{4}$, Tiziana Braccini ${ }^{1}$, Gianni Pozzi ${ }^{1}$, Marco R. Oggioni ${ }^{5,2}$, Uwe Koedel $^{4,2}$ and Stephen L. Leib ${ }^{3,2}$

\begin{abstract}
Background: Meningococcal meningitis (MM) is a life-threatening disease associated with approximately $10 \%$ case fatality rates and neurological sequelae in $10-20 \%$ of the cases. Recently, we have shown that the matrix metalloproteinase (MMP) inhibitor BB-94 reduced brain injury in a mouse model of MM. The present study aimed to assess whether doxycycline (DOX), a tetracycline that showed a neuroprotective effect as adjuvant therapy in experimental pneumococcal meningitis (PM), would also exert a beneficial effect when given as adjunctive therapy to ceftriaxone (CRO) in experimental MM.
\end{abstract}

Methods: BALB/C mice were infected by the intracisternal route with a group C Neisseria meningitidis strain. Eighteen $\mathrm{h}$ post infection (hpi), animals were randomised for treatment with CRO [100 mg/kg subcutaneously (s.c.)], CRO plus DOX (30 mg/kg s.c.) or saline (control s.c.). Antibiotic treatment was repeated 24 and $40 \mathrm{hpi}$. Mouse survival and clinical signs, bacterial counts in cerebella, brain damage, MMP-9 and cyto/chemokine levels were assessed 48 hpi.

Results: Analysis of bacterial load in cerebella indicated that CRO and CRO + DOX were equally effective at controlling meningococcal replication. No differences in survival were observed between mice treated with CRO (94.4\%) or CRO + DOX (95.5\%), ( $p>0.05)$. Treatment with CRO + DOX significantly diminished both the number of cerebral hemorrhages $(p=0.029)$ and the amount of MMP-9 in the brain $(p=0.046)$ compared to untreated controls, but not to CRO-treated animals ( $p>0.05)$. Levels of inflammatory markers in the brain of mice that received $C R O$ or $C R O+D O X$ were not significantly different $(p>0.05)$. Overall, there were no significant differences in the parameters assessed between the groups treated with CRO alone or CRO + DOX.

(Continued on next page)

\footnotetext{
* Correspondence: susanna.ricci@unisi.it

'Department of Medical Biotechnologies, Laboratory of Molecular

Microbiology and Biotechnology (LA.M.M.B.), Ospedale Santa Maria alle Scotte, University of Siena, Siena, Italy

${ }^{2}$ ESCMID Study Group for Infectious Diseases of the Brain (ESGIB), Basel, Switzerland

Full list of author information is available at the end of the article
}

(C) The Author(s). 2020 Open Access This article is licensed under a Creative Commons Attribution 4.0 International License, which permits use, sharing, adaptation, distribution and reproduction in any medium or format, as long as you give appropriate credit to the original author(s) and the source, provide a link to the Creative Commons licence, and indicate if changes were made. The images or other third party material in this article are included in the article's Creative Commons licence, unless indicated otherwise in a credit line to the material. If material is not included in the article's Creative Commons licence and your intended use is not permitted by statutory regulation or exceeds the permitted use, you will need to obtain permission directly from the copyright holder. To view a copy of this licence, visit http://creativecommons.org/licenses/by/4.0/ The Creative Commons Public Domain Dedication waiver (http://creativecommons.org/publicdomain/zero/1.0/) applies to the data made available in this article, unless otherwise stated in a credit line to the data. 


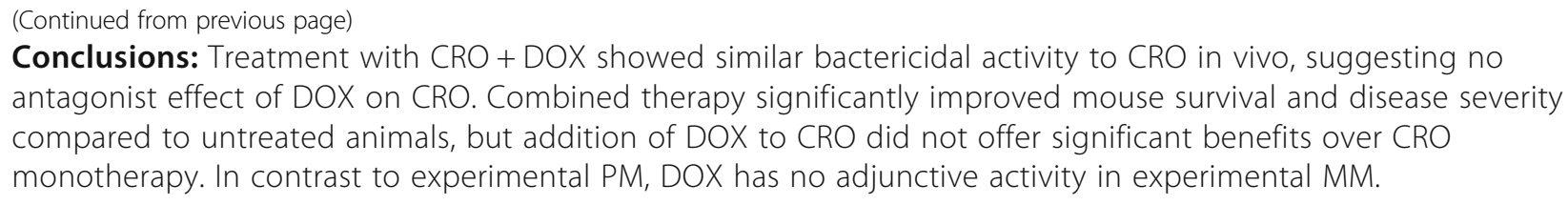

Keywords: Neisseria meningitidis, Meningococcal meningitis, Mouse model, Doxycycline, Adjunctive therapy, Brain damage, Matrix metalloproteinases

\section{Background}

Meningitis is an inflammation of the meninges and subarachnoid space that may also involve the cerebral cortex and parenchyma. Neisseria meningitidis is the second most common cause of bacterial meningitis (BM) after Streptococcus pneumoniae worldwide [1]. About 10-30\% of the human population asymptomatically carries the meningococcus in the nasopharynx, which also represents the first step for transmission and onset of invasive meningococcal disease with infants, children and adolescents being the groups at higher risk [2]. The most frequent clinical presentation of invasive disease is meningococcal meningitis (MM) [2], which can affect $30-50 \%$ of patients $[3,4]$. MM is characterised by $7-18 \%$ case fatality rates depending on meningococcal serogroup and patient age $[3,4]$. Long-term physical, neurological and psychological sequelae may occur in up to $20 \%$ of survivors [5], of which about $7 \%$ suffer from neurological sequelae (i.e., hearing loss, cognitive impairment, motor deficits, seizures) [6].

Both the host inflammatory and immune response to infection and the direct cytotoxicity of bacterial factors contribute to brain damage [7-9]. Histopathological studies in humans report different forms of brain injury associated with BM, including brain edema, hydrocephalus, cortical necrosis, petechial hemorrhages, loss of myelinated fibers in the white matter, hippocampal apoptosis, and injury to the inner ear [1,7-9]. There are numerous mediators of brain damage, including matrix metalloproteinases (MMPs). MMPs are proteolytic enzymes which can act as both proteinases by degrading extracellular matrix components and convertases by activating cytokines and their receptors [10]. Therefore, MMPs play a pivotal role in the pathogenesis of BM and brain injury by promoting inflammation, disruption of the blood-brain barrier (BBB), polymorphonuclear (PMN) cell extravasation and tissue destruction $[11,12]$. MMPs are elevated in the cerebrospinal fluid (CSF) of patients with BM [13-16], and high levels of MMP-9 are significantly associated with increased risk of neurological sequelae [15] and death [16]. In experimental models of BM, MMPs have been shown to contribute to brain damage [17-19], and pharmacological inhibition of MMPs was effective at increasing animal survival and reducing both cortical injury and hippocampal apoptosis (reviewed in [12]). Amongst the MMP inhibitors tested, doxycycline (DOX) is a second generation tetracycline able to penetrate into the CSF and equipped with both antimicrobial activity and broad antiinflammatory properties [20], including inhibition of MMPs and tumor necrosis alpha converting enzyme (TACE) [21]. Adjunctive therapy with DOX in combination with ceftriaxone $(\mathrm{CRO})$ reduced mortality and injury to the brain and cochlea in infant rats infected with $S$. pneumoniae [22].

Over the past 20 years, preclinical studies on adjunctive therapy in BM have mainly focused on experimental models of pneumococcal meningitis (PM) [23]. In contrast, as humans are the only natural hosts for N. meningitidis, hardly any work has been carried out in animal models of MM. Nevertheless, a MM experimental model based on intracisternal (i.c.) infection has been developed in adult mice [24]. Evaluation of brain damage by histology and bacterial immunostaining showed the typical traits of BM, including meningeal and ventricular inflammation, vasculitis, bleeding and hippocampal apoptosis together with meningococcal localization on the meninges, in the ventricles, in the choroid plexus and also in the corpus callosum of infected mice [24, 25]. The above findings resemble the features of meningococcal meningoencephalitis in humans, as described in clinical and autopsy studies of patients with MM [26-31]. The mouse model was recently used to assess the impact of batimastat (BB-94), a broad MMP inhibitor, on $\mathrm{MM}$-associated cerebral injury [32]. Results showed that BB-94 significantly reduced cerebral bleeding and BBB breakdown, suggesting that MMPs contribute to the pathophysiology of MM and brain damage [32].

In the present study, we have assessed the efficacy of DOX given as adjunctive therapy together with CRO in experimental MM. Results showed that, although mice treated with $\mathrm{CRO}+\mathrm{DOX}$ had increased survival and reduced brain injury compared to untreated controls, combined therapy offered no significant advantages compared to CRO monotherapy.

\section{Methods}

\section{Meningococci and growth conditions}

The serogroup C 93/4286 isolate of $N$. meningitidis, belonging to the ET-37 hypervirulent lineage, was kindly 
provided by Paola Salvatore, Naples, Italy. Bacteria were cultured at $37^{\circ} \mathrm{C}$ in $5 \% \mathrm{CO}_{2}$ on chocolate $\mathrm{GC}$ agar (Oxoid, Milano, Italy) or CG broth (Oxoid) added with $1 \%(\mathrm{v} / \mathrm{v})$ Vitox, a culture medium supplement of essential growth factors (Oxoid). Inocula for mouse challenge were prepared by cultivating bacteria in GC broth until they reached an optical density at $600 \mathrm{~nm}\left(\mathrm{OD}_{600}\right)$ of 0.8-1.0 corresponding to the early/mid-logarithmic phase of growth. To determine CFU counts, an aliquot of bacterial cultures was serially diluted and plated (approximately $10^{9} \mathrm{CFU} / \mathrm{ml}$ ). Meningococci were finally frozen at $-80^{\circ} \mathrm{C}$ with $10 \%$ glycerol until use.

\section{Mice}

Six-weeks-old female BALB/c mice weighing 18-20 g were purchased from Charles River (Calco, Italy). No written permissions were required. Animals (5-8 mice/ cage) were housed in filter top cages (Tecniplast S.p.a, Varese, Italy) in a ventilated cabinet with a controlled temperature of $20-24{ }^{\circ} \mathrm{C}$ and $12 \mathrm{~h}$ light/dark cycles. Mice were given food and water ad libitum and allowed to settle in the new environment for 1 week before performing the experiments. Animal experiments were authorised by the local ethics committee 'Organismo Preposto al Benessere Animale' (document no. 26094$\mathrm{X} / 10$ ) and the Italian Ministry of Health (document no. 815/2015-PR and following amendments), and were carried out according to institutional guidelines. The study was conducted in accordance with the ARRIVE guidelines for reporting animal experiments.

\section{Model of MM-induced brain damage}

The model was developed based on a previously described MM mouse model [24]. Briefly, $2 \mathrm{~h}$ before meningococcal challenge, animals were treated with an intraperitoneal (i.p.) injection of iron dextran $(250 \mathrm{mg} /$ kg; Sigma-Aldrich, Milano, Italy). Bacteria were thawed, washed, and suspended in GC broth with iron dextran $(5 \mathrm{mg} / \mathrm{kg})$ at a final concentration of $10^{8} \mathrm{CFU} / \mathrm{ml}$. Mice were lightly anaesthetised by i.p. injection with Zoletil [(tiletamine and zolazepam hydrochloride), $15 \mathrm{mg} / \mathrm{kg}$; Virbac Srl, Milano, Italy] and Xilor [(xylazine $2 \%), 4 \mathrm{mg} /$ kg; Bio 98 Srl, Milano, Italy] and infected intracisternally (i.c.) with $10 \mu \mathrm{l}$ of the bacterial inoculum $\left(10^{6} \mathrm{CFU} /\right.$ mouse corresponding to a lethal dose killing $20 \%$ of animals, $\left.\mathrm{LD}_{20}\right)$. Mice were closely monitored, and clinical signs were recorded according to a coma scale described for rodents [33]. Animals were humanely sacrificed if/ when they reached a score of 2 .

\section{Experimental design}

Based on a previously published study of ours [32], 3 independent experiments (18-19 mice/experiment) were performed with a total of 55 mice (control, $n=15$; CRO, $n=18 ; \mathrm{CRO}+\mathrm{DOX}, n=22)$. Animals were infected by the i.c. route as described above and randomised for antibiotic treatment 18, 24 and $40 \mathrm{~h}$ post infection (hpi). Mice were injected subcutaneously (s.c.) with CRO (Fidia Farmaceutici S.p.A, Abano Terme, Padova, Italy; $100 \mathrm{mg} / \mathrm{kg}$ ) or CRO plus DOX (Calbiochem, Merck Millipore, Merck KGaA, Darmstadt, Germany; $30 \mathrm{mg} /$ $\mathrm{kg})$. Antibiotic treatment was according to Meli et al. [22]. Animals treated with both drugs received DOX first and $\mathrm{CRO}$ after $15 \mathrm{~min}$. Control mice were injected with phosphate buffered saline (PBS). Forty eight hpi, animals were lightly anaesthetised as described above and then sacrificed by i.p. injection with an overdose of Zoletil $(30 \mathrm{mg} / \mathrm{kg}$; Virbac Srl) and Xilor $(8 \mathrm{mg} / \mathrm{kg}$; Bio $98 \mathrm{Srl})$. Cervical dislocation was employed on all euthanised mice prior to sample collection.

\section{Sample collection}

Brains and cerebella were collected. Brain samples were immediately frozen in dry ice for assessment of cerebral bleeding. Cerebella were split into halves, of which one was used for CFU counts and the other was frozen in dry ice for MMP, and cyto- and chemokine analysis. Samples were not collected from animals found dead or sacrificed before 48 hpi.

\section{Bacterial counts in cerebella}

Half cerebellum from each mouse was homogenised in $1 \mathrm{ml}$ of Brain Heart Infusion (BHI; Oxoid) with 10\% glycerol by using a Falcon $70 \mu \mathrm{m}$ cell strainer (BD Biosciences, Milano, Italy). Samples were serially diluted in BHI and plated onto chocolate CG agar plates to determine CFU counts/cerebellum. Assay detection limit was $20 \mathrm{CFU} /$ cerebellum.

\section{Quantification of cyto- and chemokines}

A panel of cyto- and chemokines (TNF- $\alpha$, IL- $1 \beta$, IL- 6 , IL-10, MIP-1 $\beta$, MCP-1, IP-10, KC, TIMP-1) was quantified in cerebellum homogenates by using microsphere-based multiplex assays (Milliplex MAP mouse cytokine/chemokine magnetic bead panel, Merck Millipore, Billerica, MA, USA). Cerebella were homogenised and treated as described before [32]. The total protein content of samples was determined by the BCA protein assay (Pierce, Thermo Fischer Scientific, Reinach, Switzerland). One hundred $\mu \mathrm{g}$ of homogenate were tested in duplicate, and at least 50 beads/analyte were measured using a Bio-Plex 200 station (Bio-Rad Laboratories, Hercules, CA, USA). Calibration curves from recombinant standards were calculated with the Bio-Plex Manager software (version 4.1.1) using a fiveparameter logistic curve fitting. 


\section{Gelatin-sepharose affinity binding and gelatin zymography}

Gelatin affinity binding and zymography were performed as previously reported [32]. Briefly, gelatinases were enriched by incubating $100 \mu \mathrm{g}$ of brain homogenate (see previous section) with $20 \mu \mathrm{l}$ of Gelatin Sepharose 4B (GE Healthcare GmbH, Glattbrugg, Switzerland). Sepharose beads were washed, incubated with $2 \mathrm{X}$ zymography sample buffer, and centrifuged to elute bound proteins. Eluted proteins were subjected to electrophoresis under non-reducing conditions in polyacrylamide gels containing $1 \%(\mathrm{v} / \mathrm{v})$ type A gelatin from porcine skin (Sigma-Aldrich). After electrophoresis, the MMP catalytic sites were activated in zymography buffer, and gels were finally stained as described [32]. Gelatinolytic activity was assessed by densitometric quantification of the substrate lysis zones around $92 \mathrm{kDa}$ (pro-MMP-9) using the ImageJ analysis software [34]. Purified human neutrophil MMP-9 (Calbiochem) was used as a standard for normalization and quantification of MMP-9 as a function of the lysis zone.

\section{Analysis of cerebral bleeding}

Brain hemorrhages were analysed as previously described [35]. Briefly, brains were cut in a frontal plane into $30 \mu \mathrm{m}$-thick sections, and serial sections were photographed with a digital camera at $0.3 \mathrm{~mm}$-intervals. For each animal, the number of bleeding spots was counted on 5 comparable brain sections.

\section{Statistical analyses}

Statistical analyses were performed using GraphPad Prism (Prism 7, GraphPad Software Inc., San Diego, USA). Results are presented as mean \pm standard deviation (SD). Differences in clinical signs, cerebral bleeding, MMP-9 gelatinolytic activity and inflammatory mediators amongst the 3 mouse groups (CRO, CRO + DOX, control) were analysed by using the nonparametric Dunn's multiple comparison test $(p<0.05)$. Mouse survival was evaluated by the Kaplan-Meier survival analysis, and differences were compared using the log-rank test $(p<0.05)$.

\section{Results}

The effect of treatment with adjunctive DOX on MM outcome was investigated $48 \mathrm{hpi}$ by assessing bacterial viable counts in cerebella, mouse survival and clinical signs, brain damage, and levels of MMPs and cyto- and chemokines.

Impact of treatment with adjunctive DOX on animal survival and clinical signs

Upon sacrifice $48 \mathrm{hpi}$, the clinical score of untreated, surviving mice was $2.7 \pm 0.4(n=10)$. Antibiotic therapy significantly improved the clinical condition of animals that had received CRO $(3.5 \pm 0.5, p=0.0018 ; n=17)$ or $\mathrm{CRO}+\mathrm{DOX}(3.4 \pm 0.6, p=0.0062 ; n=21)$ compared to untreated controls, but no differences were found between the groups treated with $\mathrm{CRO}$ or $\mathrm{CRO}+\mathrm{DOX}(p>$ 0.05). Kaplan-Meier analysis showed that the survival percentages of animals treated with $\mathrm{CRO}$ or $\mathrm{CRO}+$ DOX were 94.4 and 95.5, respectively, while survival of control mice was $66.7 \%$ (Fig. 1). As observed above with the clinical scores, differences in survival between animals treated with CRO $(p=0.036)$ or $\mathrm{CRO}+\mathrm{DOX}(p=$ 0.017 ) and untreated controls were significant, but again no differences were calculated between mice treated with CRO or CRO + DOX $(p>0.05)$ (Fig. 1).

\section{CRO and CRO + DOX are equally effective at killing meningococci in the brain}

CFU counts in cerebella of untreated mice $(n=10) 48$ hpi were $2.5 \times 10^{6} \pm 7.6 \times 10^{6}$ (mean $\left.\pm \mathrm{SD}\right)$. Bacterial titers in animals treated with CRO were $3.3 \times 10^{2} \pm 7.8 \times$ $10^{2}(n=17)$, and CFU counts were below detectable levels (20 CFU/cerebellum) in 12 out of 17 mice (data not shown). Combined therapy with CRO and DOX $\left(1.6 \times 10^{2} \pm 5.5 \times 10^{2} ; n=21\right)$ was as effective as CRO at meningococcal killing, and 15/21 cerebella were found cleared from infection (data not shown). The result suggests no antagonistic effect of DOX on CRO.

\section{CRO + DOX combined therapy is not significantly more effective than CRO monotherapy at reducing cerebral bleeding in mice with MM}

Previously published results proved cerebral bleeding as a marker of MM-associated brain injury in our mouse model [32]. Therefore, the number of intracerebral hemorrhages was counted in the three animal groups. Results evidenced a pronounced reduction in the number of bleedings in mice treated with CRO $(9.6 \pm 4.6 ; n=17)$ or CRO + DOX $(8.6 \pm 5.2 ; n=21)$ compared to untreated controls $(17.5 \pm 11.7 ; n=10)$, (Fig. 2). Although this reduction reached statistical significance only for animals administered with $\mathrm{CRO}+\mathrm{DOX}$ compared to controls $(p=0.029)$, no significant differences were observed between animals treated with $\mathrm{CRO}$ and $\mathrm{CRO}+\mathrm{DOX}$ $(p>0.05)$ (Fig. 2).

\section{Adjunctive DOX has no anti-inflammatory activity in the MM model}

DOX has been shown to have broad anti-inflammatory properties, including inhibition of MMPs and reduction of cytokine release [21]. To evaluate whether DOX inhibited MMP-9, gelatin zymography was performed on protein extracts from the cerebella of $\mathrm{CRO}, \mathrm{CRO}+\mathrm{DOX}$ treated and untreated animals 48 hpi. Densitometric analysis of MMP-9 substrate lysis zones showed a 


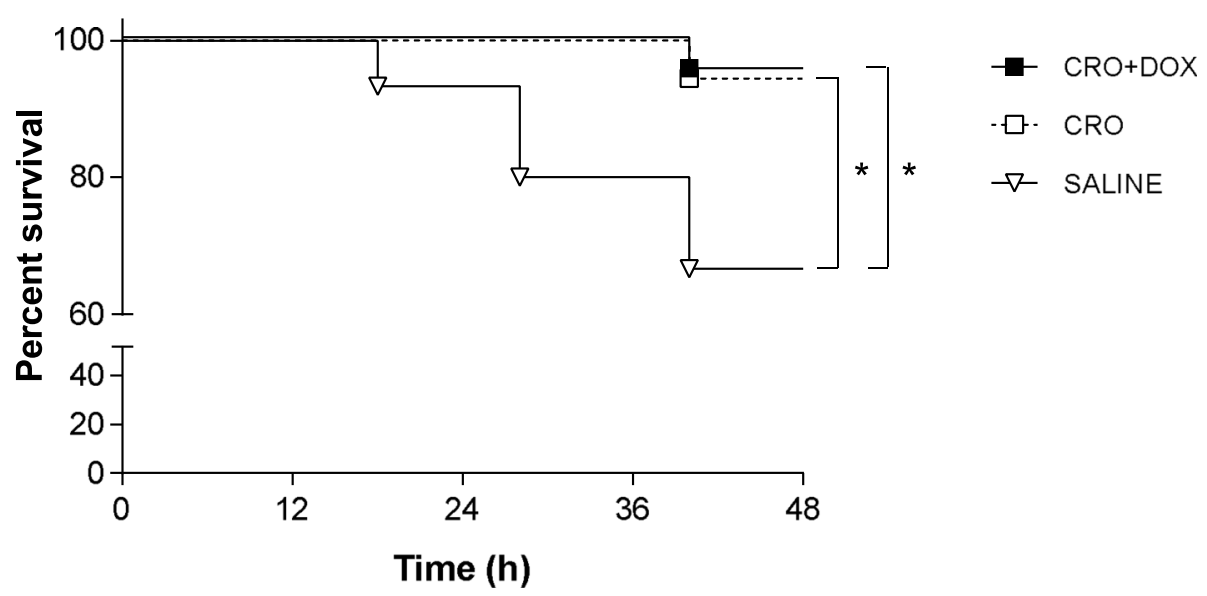

Fig. 1 Survival of mice infected with meningococci and treated with CRO + DOX. Animals were infected i.c. with N. meningitidis and randomised for treatment with CRO $(n=18), \mathrm{CRO}+\mathrm{DOX}(n=22)$ or saline (controls, $n=15) 18$ and 40 hpi. Mice were sacrificed 48 hpi. Survival curves were compared by the log-rank test. Asterisks indicate statistical significance $\left.{ }^{*}, p<0.05\right)$

reduction of MMP-9 amount in rodents treated with CRO $(0.61 \pm 0.4 ; \quad p=0.06 ; n=17)$ and $\mathrm{CRO}+\mathrm{DOX}$ $(0.58 \pm 0.2 ; p=0.046 ; n=21)$ in comparison with controls $(1 \pm 0.4 ; n=10)$, (Fig. 3). Statistical significance was observed only for the group treated with $\mathrm{CRO}+\mathrm{DOX}$. However, likewise the results on brain bleeding, no significant differences in MMP-9 levels were found between animals subjected to monotherapy and those that received the combined therapy $(p>0.05)$, indicating no adjunctive activity of DOX on CRO.

The impact of DOX on the inflammatory response was assessed by Luminex quantification of a set of inflammatory mediators in mouse cerebella. Treatment with CRO diminished inflammation, and differences with untreated mice were significant for TNF- $\alpha$ ( $p=$ $0.024)$ and IL-10 ( $p=0.0026)$, (Table 1$)$. No significant differences were observed between animals that received $\mathrm{CRO}$ alone and those subjected to CRO + DOX therapy.

\section{Discussion}

Mortality and neurological sequelae due to BM occur as a consequence of systemic and intracranial complications. In the last two decades, it became clear that a combination of antimicrobial and adjunctive therapy would represent the most desirable approach to fight the pathogen as well as control the overwhelming host response to infection $[1,8,36]$. Preclinical studies in experimental models of PM have highlighted promising targets for adjunctive therapy, including cyto- and chemokines, leukocytes, coagulation factors, oxidants, caspases, complement factors, and MMPs [36-39]. To our knowledge, there are no reports so far that have tested

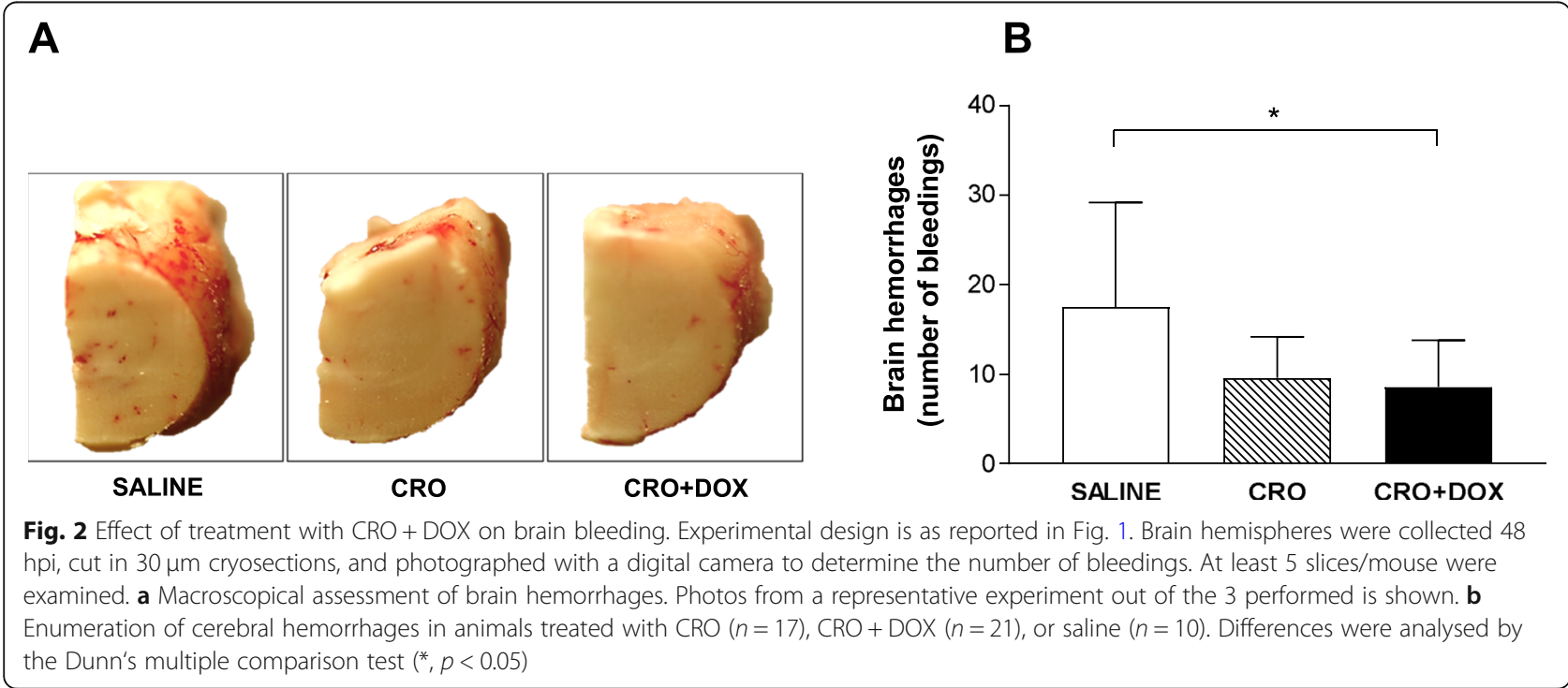




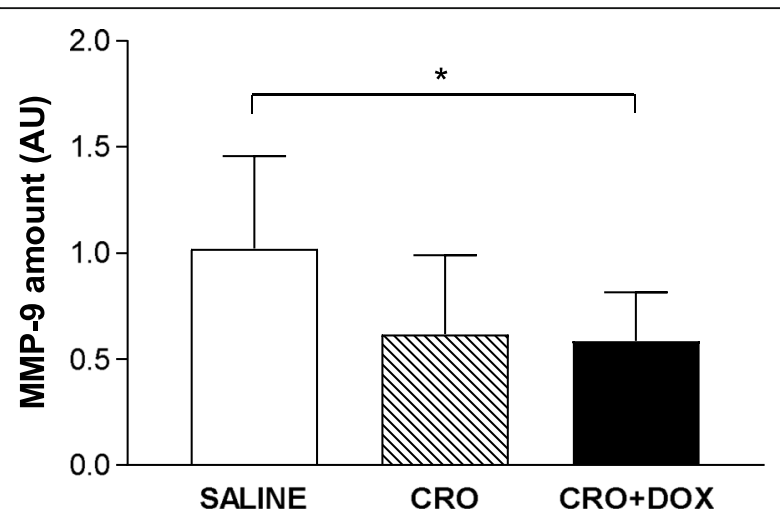

Fig. 3 Gelatin zymography on cerebella of infected mice treated with $C R O+D O X$. Animals were infected with meningococci and treated as described in Fig. 1. Cerebellum halves were homogenised, incubated with gelatin sepharose and subjected to gelatin SDS-PAGE zymography to determine the amount of MMP-9. Human MMP-9 was used as a standard. Results from 3 independent experiments are shown. Data were analysed by the Dunn's test $\left(^{*}, p<0.05\right)$. AU, arbitrary units

adjunctive drugs in experimental MM, except for our published work reporting the beneficial effects of the MMP inhibitor batimastat in a murine model of MM [32]. In humans, the only adjuvant treatment recommended in the current BM guidelines is dexamethasone which is, however, not advised in patients suffering of MM [40]. Therefore, there is an urgent need for adjunctive therapies in MM.

In the present study, we have implemented the aforementioned mouse model [32] to more closely mimic the clinical condition of patients with acute MM. Compared to our former work where adjunctive therapy was started $1 \mathrm{~h}$ before infection and a control group treated with CRO was not included [32], here antibiotic and adjuvant treatment were initiated $18 \mathrm{hpi}$ when mice were overtly symptomatic. Results showed that $\mathrm{CRO}$ and $\mathrm{CRO}+$ DOX were equally effective at increasing mouse survival and reducing brain damage compared to untreated controls, indicating that DOX was not an added value for the clinical outcome of infected mice. Some studies have shown that the impact of adjunctive drugs on brain damage is more pronounced when given as a pretreatment $[41,42]$ or within the first few $\mathrm{h}$ after infection [33, 43] rather than when meningitis is fully developed [9]. Here, we chose to start treatment at $18 \mathrm{hpi}$ on symptomatic animals in the attempt to reproduce the clinical management of patients presenting with acute MM, and this may explain why we failed to show adjunctive activity of DOX in the model.

Several synthetic MMP inhibitors (i.e., batimastat, GM6001, BB1001, TNF-484, Ro 32-7315, Trocade, and DOX) have been tested in experimental PM, and different outcomes were observed in infected animals [12]. Cortical necrosis was consistently attenuated with all inhibitors [18, 22, 33, 41-46], while reduced hippocampal apoptosis [33, 41, 44, 45], increased survival [22, 33, 41, $45,46]$, decreased hearing loss [22, 46], and improved learning and memory functions [41, 44, 45, 47] were achieved with specific molecules.

The efficacy of adjuvant DOX was assessed in two separate studies where the molecule was tested alone [22] or in combination with daptomycin [46] in an infant rat model of PM. In both reports, adjunctive DOX proved to be very effective at improving animal survival, reducing injury to brain and cochlea, and diminishing hearing loss compared to rats administered with CRO $[22,46]$. In our case, animals in the CRO + DOX group presented improved clinical scores $(p=0.0062)$, increased survival $(p=0.017)$, reduced cerebral hemorrhages $(p=0.029)$, and lower levels of MMP-9 in the brain $(p=0.046)$ in comparison with untreated controls. These results are consistent with our previous work [32] which showed that batimastat significantly diminished brain damage compared to untreated mice. That study, while proving the efficacy of batimastat as an MMP inhibitor in experimental MM, did not assess its value as an adjunctive drug since a treatment group with CRO monotherapy was not included [32]. According to our findings on cerebral bleeding and MMP-9 (Figs. 2 and 3 ), combined therapy seemed to be more neuroprotective than CRO. However, the slightly larger animal size of CRO + DOX $(n=22)$ compared to CRO $(n=18)$ may have biased the outcome of statistical analysis. Regarding the MMP-9 data, as gelatin zymography measured MMP-9 levels rather than its enzymatic activity, the present results do not allow to infer whether DOX

Table 1 Quantification of inflammatory mediators in cerebella of infected mice

\begin{tabular}{|c|c|c|c|c|c|c|c|c|c|}
\hline \multirow[t]{2}{*}{ Group $^{a}$} & \multicolumn{9}{|c|}{ Analyte $(\mathrm{pg} / \mathrm{ml})^{\mathrm{b}}$} \\
\hline & TNF-a & $\mathrm{IL}-1 \beta$ & IL-6 & IL-10 & MIP-1 $\beta$ & MCP-1 & IP-10 & KC & TIMP-1 \\
\hline Saline & $4.2 \pm 2.5$ & $287 \pm 48$ & $1283 \pm 1261$ & $10.5 \pm 7.1$ & $478 \pm 260$ & $4317 \pm 4082$ & $357 \pm 208$ & $1991 \pm 1312$ & $39,689 \pm 22,705$ \\
\hline CRO & $1.5^{*} \pm 0.8$ & $246 \pm 66$ & $100 \pm 107$ & $2.5^{* *} \pm 2$ & $132 \pm 108$ & $777 \pm 1130$ & $227 \pm 144$ & $478 \pm 196$ & $21,273 \pm 12,715$ \\
\hline CRO + DOX & $2.7 \pm 1.5$ & $249 \pm 70$ & $1182 \pm 1273$ & $3.9 \pm 1.6$ & $510 \pm 370$ & $4322 \pm 4373$ & $687 \pm 572$ & $2218 \pm 2426$ & $25,617 \pm 10,617$ \\
\hline
\end{tabular}

aice were divided in 3 groups based on treatment: saline (control), CRO or CRO + DOX

${ }^{b}$ refer to the results of statistical analysis

$*^{* * *}$, statistically significant differences compared to control mice (saline); ${ }^{*}, p<0.05 ;{ }^{* *}, p<0.01$ 
had an impact on MMP-9 activity in vivo. In contrast to the literature on adjuvant DOX in experimental PM [22, 46], in our case no significant differences in clinical parameters, inflammatory mediators and brain damage emerged between $\mathrm{CRO}$ and $\mathrm{CRO}+\mathrm{DOX}$, suggesting that adjunctive DOX does not offer significant benefits over CRO monotherapy in the MM model.

\section{Conclusions}

Opposite to the proven efficacy of adjunctive DOX in experimental PM, the present data indicate that combined therapy with CRO and DOX does not improve the outcome of MM in mice compared to CRO monotherapy. However, this negative finding is still of importance as it underlines the differences between MM and PM, and reinforces the need of testing novel adjunctive drugs in preclinical studies of MM.

\section{Abbreviations}

BM: Bacterial meningitis; MM: Meningococcal meningitis; PM: Pneumococcal meningitis; MMP: Matrix metalloproteinase; BBB: Blood-brain barrier; CSF: Cerebrospinal fluid; i.c.: Intracisternally; i.p.: Intraperitoneally; s.c.: Subcutaneously; $L_{20}$ : Lethal dose killing $20 \%$ of animals; hpi: Hours post infection; PBS: Phosphate buffered saline; CRO: Ceftriaxone;

DOX: Doxycycline; CFU: Colony forming units; TNF-a: Tumor necrosis factor a; TACE: TNF-a converting enzyme; IL: Interleukin; MCP-1: Monocyte chemoattractant protein 1; MIP-1 $\beta$ : Macrophage inflammatory protein $1 \beta$; IP10 (CXCL10): Interferon $\gamma$-induced protein 10; KC (CXCL1): Keratinocyte chemoattractant; TIMP-1: TIMP metalloproteinase inhibitor

\section{Acknowledgements}

We would like to thank Paola Salvatore and Roberta Colicchio (University of Naples Federico II, Italy) for providing the 93/4286 meningococcal strain.

\section{Authors' contributions}

SR, design and co-ordination of the study, data analysis and interpretation, supervision of animal work, manuscript writing, funding acquisition. DG, assessment of MMP levels and quantification of cyto- and chemokines, critical reading of the manuscript; IM, analysis of brain bleeding; TB, animal experiments; GP, critical reading of the manuscript, funding acquisition; $M R O$ experimental design, critical reading of the manuscript. SLL and UK, study conception and design, critical reading of the manuscript. All authors have read and approved the manuscript.

\section{Authors' information}

Laboratory of Molecular Microbiology and Biotechnology (LA.M.M.B.), Department of Medical Biotechnologies, Ospedale Santa Maria alle Scotte (V lotto, piano 1), University of Siena, 53100 Siena, Italy; Institute for Infectious Diseases, University of Bern, 3010 Bern, Switzerland; Department of Neurology, Klinikum Großhadern, Ludwig-Maximilians University, 81377 Munich, Germany; Department of Genetics, University of Leicester, Leicester LE1 7RH, UK

\section{Funding}

The study was supported by grant 'Progetti di Rilevante Interesse Nazionale' (PRIN) 2012 to GP and ESCMID Study Group Research Grant (to SR). Additional support was provided by the Swiss National Science Foundation Grants no. 189136 to SLL. None of the funding bodies had a role in the design of the study, collection, analysis, and interpretation of data and in writing the manuscript.

\section{Availability of data and materials}

The datasets used and/or analysed during the current study are available from the corresponding author on reasonable request.

\section{Ethics approval and consent to participate}

Animal experiments were authorised by the local ethics committee OPBA ('Organismo Preposto al Benessere degli Animali'; document no. 26094-X/10) and the Italian Ministry of Health (document no. 815/2015-PR and following amendments).

\section{Consent for publication}

Not applicable.

\section{Competing interests}

The authors declare that they have no competing interests.

\section{Author details}

${ }^{1}$ Department of Medical Biotechnologies, Laboratory of Molecular Microbiology and Biotechnology (LA.M.M.B.), Ospedale Santa Maria alle Scotte, University of Siena, Siena, Italy. ${ }^{2}$ ESCMID Study Group for Infectious Diseases of the Brain (ESGIB), Basel, Switzerland. ${ }^{3}$ Institute for Infectious Diseases, University of Bern, Bern, Switzerland. ${ }^{4}$ Department of Neurology, Ludwig-Maximilians University, Munich, Germany. ${ }^{5}$ Department of Genetics and Genome Biology, University of Leicester, Leicester, UK.

Received: 15 April 2020 Accepted: 3 July 2020

Published online: 13 July 2020

\section{References}

1. van de Beek D, Brouwer M, Hasbun R, Koedel U, Whitney CG, Wijdicks E. Community-acquired bacterial meningitis. Nature Rev Dis Primers. 2016;2: 16074.

2. Pace D, Pollard AJ. Meningococcal disease: clinical presentation and sequelae. Vaccine. 2012;30S:B3-9.

3. Centers for Disease Control and Prevention. Active Bacterial Core Surveillance Report. In: Emerging Infections Program Network, Neisseria meningitidis. 2018. http://www.cdc.gov/abcs/reports-findings/survreports/ mening18.pdf

4. European Centre for Disease Prevention and Control. Invasive meningococcal disease. In: ECDC. Annual epidemiological report for 2017. Stockolm: ECDC; 2019.

5. Olbrich KJ, Muller D, Schumacher S, Beck E. Systematic review of invasive meningococcal disease: sequelae and quality of life impact on patients and their caregivers. Infect Dis Ther. 2018;7:421-38.

6. Edmond K, Clark A, Korczak VS, Sanderson C, Griffiths UK, Rudan I. Global and regional risk of disabling sequelae from bacterial meningitis: a systematic review and meta-analysis. Lancet Infect Dis. 2010;10:317-28.

7. Koedel U, Klein M, Pfister H-W. New understandings on the pathophysiology of bacterial meningitis. Curr Opin Infect Dis. 2010;23:217-23.

8. Gerber J, Nau R. Mechanisms of injury in bacterial meningitis. Curr Opin Neurol. 2010;23:312-8.

9. Liechti FD, Grandgirard D, Leib SL. Bacterial meningitis: insights into pathogenesis and evaluation of new treatment options: a perspective from experimental studies. Future Microbiol. 2015;10:1195-213.

10. Parks WC, Wilson CL, Lopez-Boado Y. Matrix metalloproteinases as modulators of inflammation and innate immunity. Nat Rev Immunol. 2004;4: $617-29$

11. Leppert D, Lindberg RLP, Kappos L, Leib SL. Matrix metalloproteinases: multifunctional effectors of inflammation in multiple sclerosis and bacterial meningitidis. Brain Res Rev. 2001;36:249-57.

12. Baranger K, Rivera S, Liechti FD, Grandgirard D, Bigas J, Seco J, et al Endogenous and synthetic MMP inhibitors in CNS physiopathology. Prog Brain Res. 2014:214:313-51.

13. Paul R, Lorenzl S, Koedel U, Sporer B, Vogel U, Frosch M, et al. Matrix metalloproteinases contribute to the blood-brain barrier disruption during bacterial meningitis. Ann Neurol. 1998;44:592-600.

14. Lindberg RLP, Sorsa T, Tervahartiala T, Hoffmann F, Mellanen L, Kappos L, et al. Gelatinase B [matrix metalloproteinase (MMP)-9] and collagenases (MMP-8/-13) are upregulated in cerebrospinal fluid during aseptic and bacterial meningitis in children. Neuropathol Appl Neurobiol. 2006:32:30417.

15. Leppert D, Leib SL, Grygar C, Miller KM, Schaad UB, Hollander GA. Matrix metalloproteinase (MMP)-8 and MMP-9 in cerebrospinal fluid during bacterial meningitis: association with blood-brain barrier damage in neurological sequelae. Clin Infect Dis. 2000;31:80-4. 
16. Roine I, Pelkonen T, Bernardino L, Lauhio A, Tervahartiala T, Lappalainen M, et al. Predictive value of cerebrospinal fluid matrix metalloproteinase-9 and tissue inhibitor of metalloproteinase-1 concentrations in childhood bacterial meningitis. Pediatr Infect Dis J. 2014;33:675-9.

17. Azeh I, Mader M, Smirnov A, Beuche W, Nau R, Weber F. Experimental pneumococcal meningitis in rabbits: the increase of matrix metalloproteinase-9 in cerebrospinal fluid correlates with leucocyte invasion. Neurosci Lett. 1998:256:127-30.

18. Leib SL, Leppert D, Clements J, Tauber MG. Matrix metalloproteinases contribute to brain damage in experimental pneumococcal meningitis. Infect Immun. 2000;68:615-20.

19. Sellner J, Leib SL. In bacterial meningitis cortical brain damage is associated with changes in parenchymal MMP-9/TIMP-1 ratio and increased collagen type IV degradation. Neurobiol Dis. 2006;21:647-56.

20. Bahrami F, Morris DL, Pourgholami MH. Tetracyclines: drugs with huge therapeutic potential. Mini-Rev Med Chem. 2012;12:44-52.

21. Acharya MR, Venitz J, Figg WD, Sparreboom A. Chemically modified tetracyclines as inhibitors of matrix metalloproteinases. Drug Resist Updat. 2004;7:195-208

22. Meli DN, Coimbra RS, Erhart DG, Loquet G, Bellac C, Tauber MG, et al. Doxycycline reduces mortality and injury to the brain and cochlea in experimental pneumococcal meningitis. Infect Immun. 2006;74:3890-6.

23. Bewersdorf JP, Grandgirard D, Koedel U, Leib SL. Novel and preclinical treatment strategies in pneumococcal meningitis. Curr Opin Infect Dis. 2018;31:85-92

24. Colicchio R, Ricci S, Lamberti F, Pagliarulo C, Pagliuca C, Braione V, et al. The meningococcal $A B C$-type L-glutamate transporter GltT is necessary for the development of experimental meningitis in mice. Infect Immun. 2009;77: 3578-87.

25. Colicchio R, Pagliuca C, Ricci S, Scaglione E, Grandgirard D, Masouris I, et al. Virulence traits of a serogroup C meningococcus and isogenic CSSA mutant, defective in surface-exposed sialic acid, in a murine model of meningitis. Infect Immun. 2019;87:e00688-18.

26. van Deuren $M$, Brandtzaeg $P$, van der Meer JWM. Update on meningococcal disease with emphasis on pathogenesis and clinical management. Clin Microbiol Rev. 2000;13:144-66.

27. Pron B, Taha M-K, Rambaud C, Fournet J-C, Pattey N, Monnet J-P, et al. Interaction of Neisseria meningitidis with the components of the blood-brain barrier correlates with an increased expression of PilC. J Infect Dis. 1997;176: 1285-92.

28. Guarner J, Greer PW, Whitney A, Shieh W-J, Fischer M, White EH, et al. Pathogenesis and diagnosis of human meningococcal disease using immunohistochemical and PCR assays. Am J Clin Pathol. 2004;122:754-64.

29. Schut ES, Lucas MJ, Brouwer MC, Vergouwen MDI, van der Ende A, van de Beek D. Cerebral infarction in adults with bacterial meningitis. Neurocrit Care. 2012;16:421-7.

30. Miyazaki K, Fukushima H, Kogeichi Y, Watanabe T, Norimoto K, Taoka T, et al. A case of meningococcal meningitis with multiple cerebellar microbleeds detected by susceptibility-weighted imaging. BMC Med Imaging. 2015;15:45.

31. Ventura F, Bonsignore A, Portunato F, Orcioni GF, Varnier OE, De Stefano F. A fatal case of streptococcal and meningococcal meningitis in a 2-years-old child occurring as Waterhouse-Friderichsen syndrome. J Forensic Legal Med. 2013;20:678-82

32. Ricci S, Grandgirard D, Wenzel M, Braccini T, Salvatore P, Oggioni MR, et al. Inhibition of matrix metalloproteinases attenuates brain damage in experimental meningococcal meningitis. BMC Infect Dis. 2014;14:726.

33. Liechti FD, Grandgirard D, Leppert D, Leib SL. Matrix metalloproteinase inhibition lowers mortality and brain injury in experimental pneumococcal meningitis. Infect Immun. 2014;82:1710-8.

34. Schneider CA, Rasband WS, Eliceiri KW. NIH image to ImageJ: 25 years of image analysis. Nat Methods. 2012:9:671-5.

35. Koedel U, Frankenberg T, Kirschnek S, Obermaier B, Hacker H, Paul R, et al. Apoptosis is essential for neutrophil functional shutdown and determines tissue damage in experimental pneumococcal menigitis. PLoS Pathog. 2009; 5:e1000461.

36. Koedel U, Klein M, Pfister H-W. Modulation of brain injury as a target of adjunctive therapy in bacterial meningitis. Curr Infect Dis Rep. 2010;12:266-73.

37. van der Flier M, Geelen SP, Kimpen JL, Hoepelman IM, Tuomanen El. Reprogramming the host response in bacterial meningitis: how best to improve outcome? Clin Microbiol Rev. 2003:16:415-29.
38. Barichello T, Collodel A, Generoso JS, Simões LR, Moreira AP, Ceretta RA, et al. Targets for adjunctive therapy in pneumococcal meningitis. J Neuroimmunol. 2015;278:262-70.

39. Klein M, Hohne C, Angele B, Hogen T, Pfister HW, Tufekci H, et al. Adjuvant non-bacteriolytic and anti-inflammatory combination therapy in pneumococcal meningitis: an investigation in a mouse model. Clin Microbiol Infect. 2019:25:108.e9-108.e15.

40. van de Beek D, Cabellos C, Dzupova O, Esposito S, Klein M, Kloek AT, et al. ESCMID guideline: diagnosis and treatment of acute bacterial meningitis. Clin Microbiol Infect. 2016;22:S37-62.

41. Leib SL, Clements JM, Lindberg RLP, Heimgartner C, Loeffler JM, Pfister L-A, et al. Inhibition of matrix metalloproteinases and tumour necrosis factor a converting enzyme as adjuvant therapy in pneumococcal meningitis. Brain. 2001;124:1734-42

42. Meli DN, Loeffler JM, Baumann P, Neumann U, Buhl T, Leppert D, et al. In pneumococcal meningitis a novel water-soluble inhibitor of matrix metalloproteinases and TNF-a converting enzyme attenuates seizures and injury of the cerebral cortex. J Neuroimmunol. 2004;151:6-11.

43. Liechti FD, Bachtold F, Grandgirard D, Leppert D, Leib SL. The matrix metalloproteinase inhibitor RS-130830 attenuates brain injury in experimental pneumococcal meningitis. J Neuroinflammation. 2015;12:43.

44. Liu X, Han Q. Efficacy of GM6001 as an adjuvant to ceftriaxone in a neonatal rat model of Streptococcus pneumoniae meningitis. Acta Neurobiol Exp (Wars). 2014;74:489-96.

45. Muri L, Grandgirard D, Buri M, Perny M, Leib SL. Combined effect of nonbacteriolytic antibiotic and inhibition of matrix metalloproteinases prevents brain injury and preserves learning, memory and hearing function in experimental paediatric pneumococcal meningitis. J Neuroinflammation. 2018;15:233.

46. Muri L, Perny M, Zemp J, Grandgirard D, Leib SL. Combining ceftriaxone with doxycycline and daptomycin reduces mortality, neuroinflammation, brain damage, and hearing loss in infant rat pneumococcal meningitis. Antimicrob Agents Chemother. 2019;63:e00220-19.

47. Barichello T, Generoso JS, Michelon CM, Simoes LR, Elias SG, Vuolo F, et al Inhibition of matrix metalloproteinases-2 and -9 prevents cognitive impairment induced by pneumococcal meningitis in Wistar rats. Exp Biol Med. 2014;239:225-31.

\section{Publisher's Note}

Springer Nature remains neutral with regard to jurisdictional claims in published maps and institutional affiliations.

Ready to submit your research? Choose BMC and benefit from:

- fast, convenient online submission

- thorough peer review by experienced researchers in your field

- rapid publication on acceptance

- support for research data, including large and complex data types

- gold Open Access which fosters wider collaboration and increased citations

- maximum visibility for your research: over $100 \mathrm{M}$ website views per year

At $\mathrm{BMC}$, research is always in progress.

Learn more biomedcentral.com/submission 